\title{
DISCORDANCE IS THE KEY
}

\author{
K. Nagendra Prasad, A. Ashok Kumar
}

\begin{abstract}
: Congenitally corrected transposition of the great arteries (CCTGA) is a rare form of congenital heart disease characterised by atrioventricular as well as ventriculoarterial discordance. It is usually associated with a variety of severe intracardiac defects. Few patients with this abnormality survive past 50 years. A $54 \mathrm{Yr}$ old male patient referred to our hospital for the management of post MI VSD. At the presentation Patient had mild central cyanosis, clubbing grade 2 and the vitals are stable. Cardiac examination revealed a 2/6 long ESM in a left parasternal area with pulsations in left $2^{\text {nd }}$ and $3^{\text {rd }}$ ICS. There is a lot of discrepancy in both clinical examination and workup. After detailed evaluation patient is diagnosed as having cyanotic congenital heart disease - L TGA + VSD with PS. Survival up to this age is very rare with this combination of associated defects in LTG. The patient is misdiagnosed as coronary artery disease with mechanical complication in another hospital. Unless there is suspicion and having knowledge about the asymptomatic presentation of congenital heart diseases up to this age group, patients will be misdiagnosed and treatment will be delayed.
\end{abstract}

Keywords: CCTGA-Congenital corrected transposition of great artery, VSD- ventricular septal defect, MI- myocardial infarction, ICS- intercostal space, ESM - ejection systolic murmur, CVS- cardiovascular system, PS - pulmonary stenosis, FA-femoral artery, PA- pulmonary artery, TPI temporary pacemaker implantation

\section{INTRODUCTION:}

The Congenitally corrected transposition of the great arteries (CCTGA) is a rare form of congenital heart disease first described by Von Rokitansky in 1875 and characterised by atrioventricular and ventriculoarterial discordance. The atrioventricular discordance implies that the morphological right atrium drains into the morphological left ventricle (LV) and the morphological left atrium into the morphological right ventricle $(\mathrm{RV})$. Thus, the LV supplies the pulmonary circulation, and the RV supports the systemic circulation. CCTGA accounts for less than $1 \%$ of

Article received on 01 JAN 2017, published on 31JAN 2017.

K.Nagendra Prasad ${ }^{1}$, A.Ashok Kumar ${ }^{1}$

${ }^{1}$ Senior Resident, Department of Cardiology, NIMS, India

Corresponding Author: K.Nagendra Prasad

Email: nagendra.kulari@gmail.com congenital heart disease cases and is usually associated with a severely reduced life expectancy owing to ventricular septal defects $(74 \%)$, pulmonary valvar stenosis (74\%), systemic (tricuspid) valve Abnormalities (38\%) and complete heart block (5\%). Only $1-10 \%$ of individuals with CCTGA have no associated defects. Their life expectancy is limited by the onset of systemic (morphologically right) ventricular failure in their 40 s or 50 s.

\section{CASE REPORT:}

A 54 Year old male patient who is non-hypertensive and non-Diabetic, smoker and manual laborer by occupation referred from another hospital for the management of Acute coronary syndrome with post MI VSD. The patient had an episode of mild chest pain and shortness of breath 1 week back. Apart from this, there are no other significant complaints. On examination, there is mild central cyanosis and grade 2 clubbing. Cyanosis is very subtle. Vitals are stable and CVS examination showed normal s1 and single s2, grade 2/6 long ESM in a left parasternal area with pulsations in left $2^{\text {nd }}$ and $3^{\text {rd }}$ ICS. Lungs have normal vesicular breath sounds. All these findings are not consistent with the patient provisional diagnosis.

CXR showed pulmonary oligemia with wide vascular pedicle. Mesocardia is present. ECG showed 1 'heartblock $\mathrm{Q}$ and $\mathrm{T}$ inversion in lead 1 and $\mathrm{AVL}, \mathrm{T}$ inversion from V2 to V6 with ST depression in v5, v6. There are a counter clockwise loop and right axis deviation of 110 (fig 1 ).

Many of the above findings are not in line with our working diagnosis. Hence we decided to pursue further for an alternate diagnosis. As there is a defect in ventricular septum we did segmental analysis of heart in echo which showed there is double discordance with large subaortic VSD with inlet extension and bidirectional shunt across VSD with severe subvalvular and valvular Pulmonary Stenosis (gradient of $60 \mathrm{~mm}$ hg) and good Bi-ventricular function. There is no left $\mathrm{AV}$ valve regurgitation (fig 2).

Keeping all the information gained from above investigations we proceeded to catheterization test after inserting TPI prophylactically before the 
procedure. Pressure data showed equal pressure in both ventricles $(R V=L V=124 / 0-6 \mathrm{~mm} h)$ suggestive of a nonrestrictive VSD. We were unable to enter PA and There is gross systemic desaturation (FA$82 \%)$.There is a significant step up at ventricular level.
Right sided ventricular angiogram has showed finely trabeculated LV with narrowing at subvalvular and valvular level in the pulmonary artery. Left sided ventricular angiogram showed coarsely trabeculated RV with dilated left sided aorta (fig 3).

Fig 1: CXR - wide vascular pedicle, pulmonary oligemia \& ECG
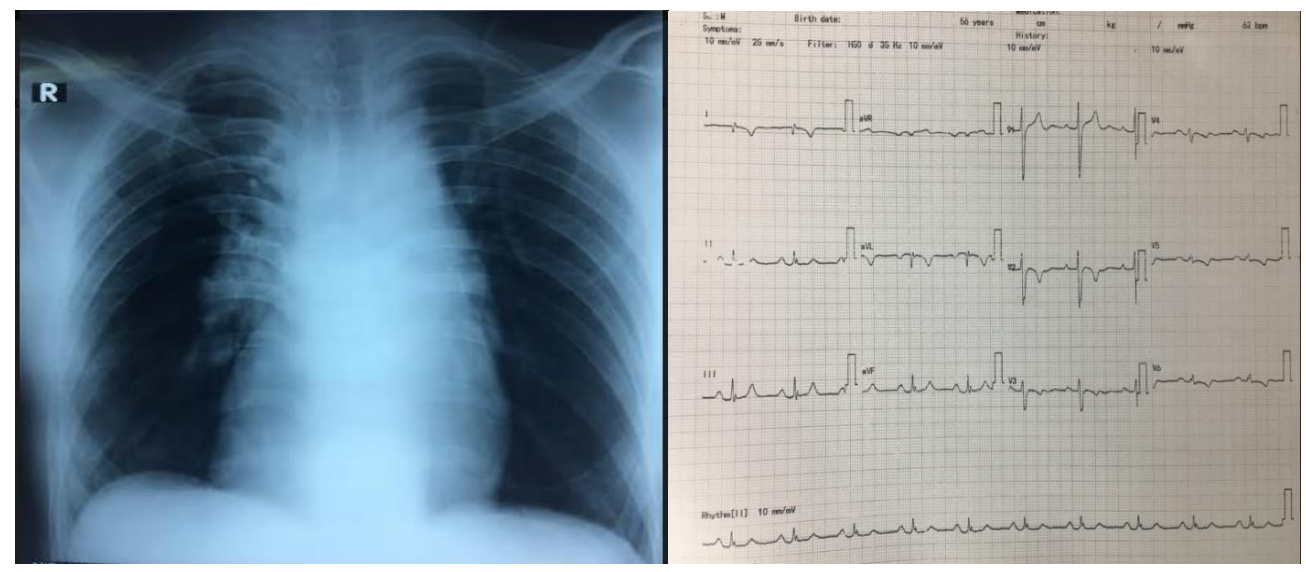

Fig 2: ECHO
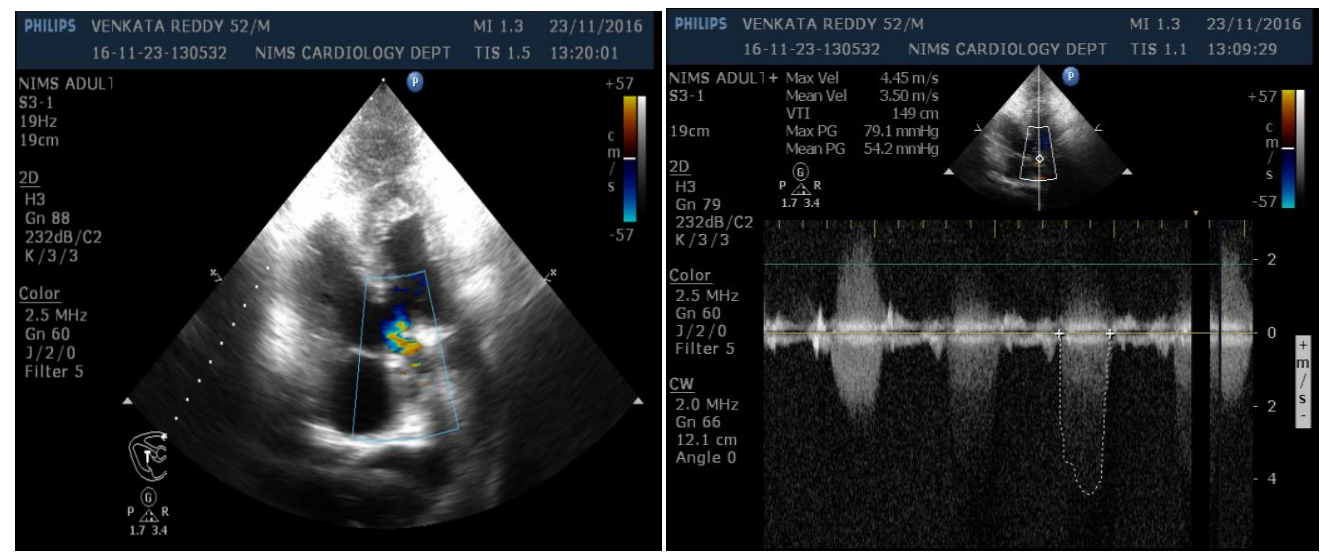

Fig 3: RV and LV angiograms

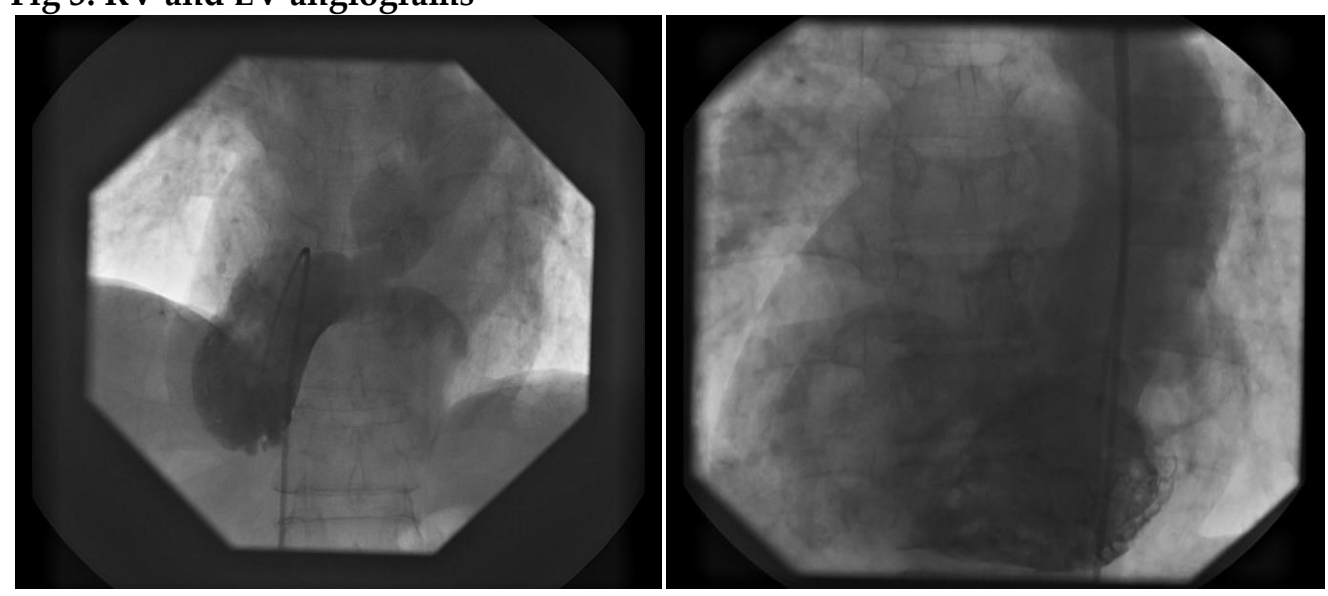


Final catheterization diagnosis was LTGA + VSD with severe PS with confluent pulmonary arteries and bidirectional shunt at VSD level, normal coronaries. The patient was sent for intracardiac repair.

\section{DISCUSSION:}

L-TGA is a rare form of congenital heart disease with a published incidence ranging from 0.02 to 0.07 per 1000 live births, accounting for less than 1 percent of congenital heart lesions [1-3]. Patients with CCTGA rarely survive to old age. The natural history of L-TGA is largely determined by the presence of associated cardiac abnormalities and the progressive dysfunction of the morphologic RV as the systemic pump [1-3]. By the age of 45 years, two-thirds of patients with associated lesions and one-quarter of patients without additional cardiac defects had developed heart failure symptoms. The risk of systemic ventricular dysfunction, systemic AV valve regurgitation, and ongoing rhythm disturbances increases with advancing age. Asymptomatic presentation of LTGA+VSD with PS up to $5^{\text {th }}$ decade is very rare and probably this is the first case report of this category. This patient is diagnosed as having acute coronary syndrome based on history, clinical examination, ECG in another hospital. Even though post MI VSD is a dreaded complication with mortality rates of $90-95 \%$, some of these patients can present with minimal symptoms after 1-2 weeks. likewise, Some of congenital heart defects like L TGA with VSD, Ebstein anomaly will present without symptoms up to 4 th or 5th decade depending on the complexity of the defect. So whenever we encounter a patient with heart defect, we should thoroughly evaluate the patient keeping all the possibilities in mind. Here, in this case, patient is misdiagnosed as Acute coronary syndrome with ventricular septal rupture based on the ECHO and other limited data by the treating physician. But in view of discordant findings in both clinical examination and ECG, we did segmental analysis by ECHO followed by cardiac catheterization which finally concluded the presence of cyanotic congenital heart disease. In L-TGA, the interventricular septum is depolarized in the opposite direction of normal. This results in the characteristic ECG findings of $Q$ waves in the right precordial leads and an absence of $Q$ waves in the left-sided precordial leads [9]. These ECG findings may be misinterpreted as an inferior myocardial infarction [8]. Twenty-five percent of patients with LTGA will have Mesocardia or Dextrocardia [7]. In patients with CCTGA, systemic ventricular failure is the cause of death in more than $50 \%$ [10]

\section{REFERENCES :}

1. Ferencz C, Rubin JD, McCarter RJ, et al. Congenital heart disease: prevalence at live birth. The BaltimoreWashington Infant Study. Am J Epidemiol 1985; 121:31.

2. Report of the New England Regional Infant Cardiac Program. Pediatrics 1980; 65:375.

3. Samanek M, Voriskova M. Congenital heart disease among 815,569 children born between 1980 and 1990 and their 15-year survival: a prospective Bohemia survival study. Pediatr Cardiol 1999; 20:411.

4. Graham TP Jr, Bernard YD, Mellen BG, et al. Longterm outcome in congenitally corrected transposition of the great arteries: a multi-institutional study. J Am Coll Cardiol 2000; 36:255.

5. Beauchesne LM, Warnes CA, Connolly HM, et al. Outcome of the unoperated adult who presents with congenitally corrected transposition of the great arteries. J Am Coll Cardiol 2002; 40:285.

6. Murtuza B, Barron DJ, Stumper O, et al. Anatomic repair for congenitally corrected transposition of the great arteries: a single-institution 19-year experience. J Thorac Cardiovasc Surg 2011; 142:1348.

7. Dyck JD, Atallah JA. Transposition of the great arteries. In: Moss and Adams' Heart Disease in Infants, Children, and Adolescents: Including the Fetus and Young Adult, 7th ed, Allen HD, Shaddy RE, Driscoll DJ, Feltes TF (Eds), Wolters Kluwer Health/Lippincott Williams \& Wilkins, Philadelphia 2008. p.1087.

8. Warnes CA. Transposition of the great arteries. Circulation 2006; 114:2699.

9. Hornung TS, Kilner PJ, Davlouros PA, et al. Excessive right ventricular hypertrophic response in Adults with the mustard procedure for transposition of the great arteries. Am J Cardiol 2002; 90:800. 
10. Connelly MS ,Liu PP,Williams WG, et al. Congenitally corrected transposition of the great arteries in the adult: functional status and complications. J Am Coll Cardiol 1996; 27: 1238-43. 